\title{
Novel Pharmacotherapies for Recurrent Pericarditis: Current Options in 2020
}

\author{
Enrico Tombetti ${ }^{1}$ - Alice Mulè ${ }^{2}$ Silvia Tamanini ${ }^{2} \cdot$ Luca Matteucci $^{2} \cdot$ Enrica Negro $^{2}$. \\ Antonio Brucato ${ }^{1} \cdot$ Carla Carnovale $^{3}$ (i)
}

Published online: 19 June 2020

(C) Springer Science+Business Media, LLC, part of Springer Nature 2020

\begin{abstract}
Recent advances have shown impressive results by anti-interleukin 1 (IL-1) agents in refractory idiopathic recurrent pericarditis. Purpose of Review

We critically discuss the current state of the art of therapy of relapsing pericarditis, with a focus on new pharmacological approaches and on specific clinical settings such as pregnancy, pediatric patients, and secondary forms of relapsing pericarditis.

\section{Recent Findings}

Antagonism of the IL-1 is highly effective in idiopathic recurrent pericarditis with autoinflammatory features. Currently, available anti-IL-1 agents are anakinra and canakinumab. Rilonacept is another IL-1 antagonist, currently studied in the phase-3 clinical trial RHAPSODY. Available data suggest similar efficacy and safety profiles of these three agents, although only anakinra has been tested in randomized clinical trials. These agents have slightly different pharmacological properties, being canakinumab a specific IL-1 $1 \beta$ antagonist while anakinra and rilonacept are unselective IL- $1 \alpha$ and IL- $1 \beta$ blockers. To date, there is no evidence that specificity against IL- $1 ß$ affects safety and efficacy in patients with relapsing pericarditis, although it has been proposed that unspecific blockage might be useful in severe disease.

\section{Summary}

Anakinra is the first anti-IL-1 agent with well-documented efficacy and safety in adult and pediatric patients with idiopathic relapsing pericarditis. Other anti-IL-1 agents are currently under study. Future research should clarify the optimal duration of therapy and tapering schedule of treatment with these agents. Moreover, biomarkers would be required to understand which patients will benefit from early administration of IL-1 blockers due to refractoriness to conventional therapy and which others will suffer from recurrences during the tapering of these agents. Lastly, future studies should focus on the subjects with the autoimmune or the pauci-inflammatory phenotype of idiopathic refractory pericarditis.
\end{abstract}

Keywords Anti-IL-1 drugs $\cdot$ Anakinra $\cdot$ Recurrent pericarditis $\cdot$ Inflammatory refractory pericarditis

This article is part of the Topical Collection on Pericardial Disease

Carla Carnovale

carla.carnovale@unimi.it

Enrico Tombetti

enrico.tombetti@unimi.it

Alice Mulè

alice.mule@outlook.it

Silvia Tamanini

silvia.tamanini@unimi.it

Luca Matteucci

luca.matteucci@unimi.it
Enrica Negro

enrica.negro@unimi.it

Antonio Brucato

antonio.brucato@unimi.it

Department of Biomedical and Clinical Sciences, Università di Milano, Fatebenefratelli Hospital, Milan, Italy

2 Internal Medicine, Fatebefratelli Hospital, Milan, Italy

3 Unit of Clinical Pharmacology, Department of Biomedical and Clinical Sciences L. Sacco, "Luigi Sacco" University Hospital, Università di Milano, Via GB Grassi 74, 20157 Milan, Italy 


\section{Introduction}

Pericarditis is an inflammatory disease of the pericardial sac $[1 \bullet \bullet]$. According to the 2015 European Society of Cardiology (ESC) guidelines for the diagnosis and management of pericardial diseases $[1 \bullet \bullet$, recurrent pericarditis $(\mathrm{RP})$ is defined as the occurrence of two or more episodes of acute pericarditis with an event-free period of at least 4-6 weeks. Up to $30 \%$ of acute episodes recur within 18 months without adequate therapy [2•*], and about $10 \%$ of patients with RP experience recurrences despite first- and second-line therapies, a condition known as refractory recurrent pericarditis $[1 \bullet \bullet, 3]$. RP has a good prognosis quoad vitam (i.e., scarce disease-related mortality), although the quality of life (QoL) may be severely affected, especially in patients with frequent relapses or juvenile onset $[1 \bullet \bullet$. Refractory RP represents a therapeutic challenge and is experiencing important advances in disease therapy.

Treatment of acute pericarditis should target the underlying etiology, whenever this can be identified. Most frequent etiologies show geographical variation and differ between RP and the first episode of acute pericarditis. In developed countries, most cases of RP are labeled as "idiopathic" RP (IRP) as no obvious etiologies can be identified after an exhaustive screening $[1 \bullet \bullet, 4 \bullet]$. We highlight that significant disease heterogeneity is present among subjects with IRP, requiring a tailored therapeutic approach. Based on clinical patterns and response to therapy, three main phenotypes of IRP can be recognized [4•]:

1. An autoimmune phenotype, characterized by subacute course, moderate C-reactive protein (CRP) elevation, frequent autoantibody positivity (anti-nuclear antibodies (ANA), anti-heart antibodies (AHA), anti-intercalated disk autoantibodies (AIDA)), and features occurring in systemic autoimmune diseases (e.g., arthralgias, dry eyes, Raynaud's phenomenon).

2. An autoinflammatory phenotype, characterized by recurrent relapses followed by complete resolution, highly symptomatic serositis, strikingly high CRP, and high fever. Autoantibodies are frequently absent.

3. An aspecific phenotype, characterized by mildly symptomatic patients with few attacks, subacute course, smoldering elevation of inflammatory markers, no evidence of autoimmunity.

It is proposed that relevant pathogenic differences underlay these phenotypic heterogeneities. Indeed, studies have shown that IRP-associated inflammation might be driven by autoimmune and/or autoinflammatory mechanisms [4•]. Autoimmunity is suggested by the occurrence of RP in many systemic autoimmune diseases and by the detection of high titers of AHA and AIDA in up to $67.5 \%$ of IRP patients [5•].
However, the mere presence of autoantibodies does not definitively prove a pathogenic role of autoimmunity, as they may be an epiphenomenon of pericardial inflammation. Intrinsic dysregulation of innate immunity (i.e., auto-inflammation) is suggested by familiar aggregation and similarities with some autoinflammatory diseases, such as Familial Mediterranean Fever (FMF), or tumor necrosis factor receptor-associated periodic syndrome (TRAPS). Similarly to patients with FMF and TRAPS, patients with the autoinflammatory phenotype of IRP respond spectacularly to anti-interleukin-1 (IL-1) agents.

IL-1 is one of the major inflammatory cytokines: two different proteins belonging to this same family have been identified in 1985 , IL- $1 \alpha$ and IL- $1 \beta$, and have since been widely studied in relation to their proinflammatory and pyrogenic properties $[6,7]$. IL- $1 \alpha$ is constitutively present in every healthy cell type, whereas IL- $1 \beta$ is produced by leukocytes upon stimulation [8]. IL-1 $\beta$ upregulates inflammatory mediators such as cyclo-oxygenase-2 (COX-2) and prostaglandins (PG) and can drive hyperemia, edema, and hyperesthesia - all features of pericardial inflammation [9]. Multiple stimuli result in IL-1 production, including pathogen-associated molecular patterns (PAMPs), damage-associated molecular patterns (DAMPs), and other inflammatory cytokines such as TNF $\alpha$, IL-18, or IL-1 $\beta$ itself, spiraling in a vicious circle of autoinflammation [8].

Here, we review current pharmacological management of IRP - with a specific focus on recent advances represented by the advent of anti-IL1 agents in the field- and of specific clinical settings including pediatric or pregnant patients and RP secondary to post-cardiac injury, systemic autoimmune, or autoinflammatory diseases. The pathogenesis of IRP and potential pharmacological targets are shown in Fig. 1.

Specific complications of pericarditis such as cardiac tamponade and development of pericardial constriction may require interventional therapy and are beyond the scope of this review.

\section{Therapy of Idiopathic Recurrent Pericarditis}

The goals of RP treatment are (i) management of the acute episodes with the induction of remission and (ii) prevention of recurrences. Patients with pericarditis can usually be treated as an outpatient, except for those at high risk that require hospital treatment $[1 \bullet \bullet$.

First-line therapy of recurrences of IRP treatment does not differ from that for the first episode of acute idiopathic pericarditis, although it should be tapered more slowly: high-dose acetylsalicylic acid (ASA) or non-steroidal anti-inflammatory drugs (NSAIDs) and colchicine are the mainstays of therapy $[1 \bullet \cdot]$. The choice of the specific NSAID to use should be guided by patient's comorbidities, allergies, tolerance to treatment, and Physician's experience $[1 \bullet \bullet, 10]$. NSAID should be 
Fig. 1 Pathogenesis of IRP and potential pharmacological targets. DAMP damage-associated molecular pattern, PAMP pathogens-associate molecular patterns, TLR Toll-like receptor, NLR nod-like receptor, APC antigen-presenting cell, Ly lymphocytes, AHA anti-heart antibodies, AIDA antiintercalated-disk antibodies, PLA2 phospholipase-A2, COX-1 cyclooxygenase-1, TNF tumor necrosis factor, IL interleukin, IL1RA interleukin 1 receptor antagonist, IL-1R interleukin 1 receptor, NSAID nonsteroidal anti-inflammatory drugs, NFkB nuclear factor $\mathrm{k}$-light-chainenhancer of activated $B$ cells

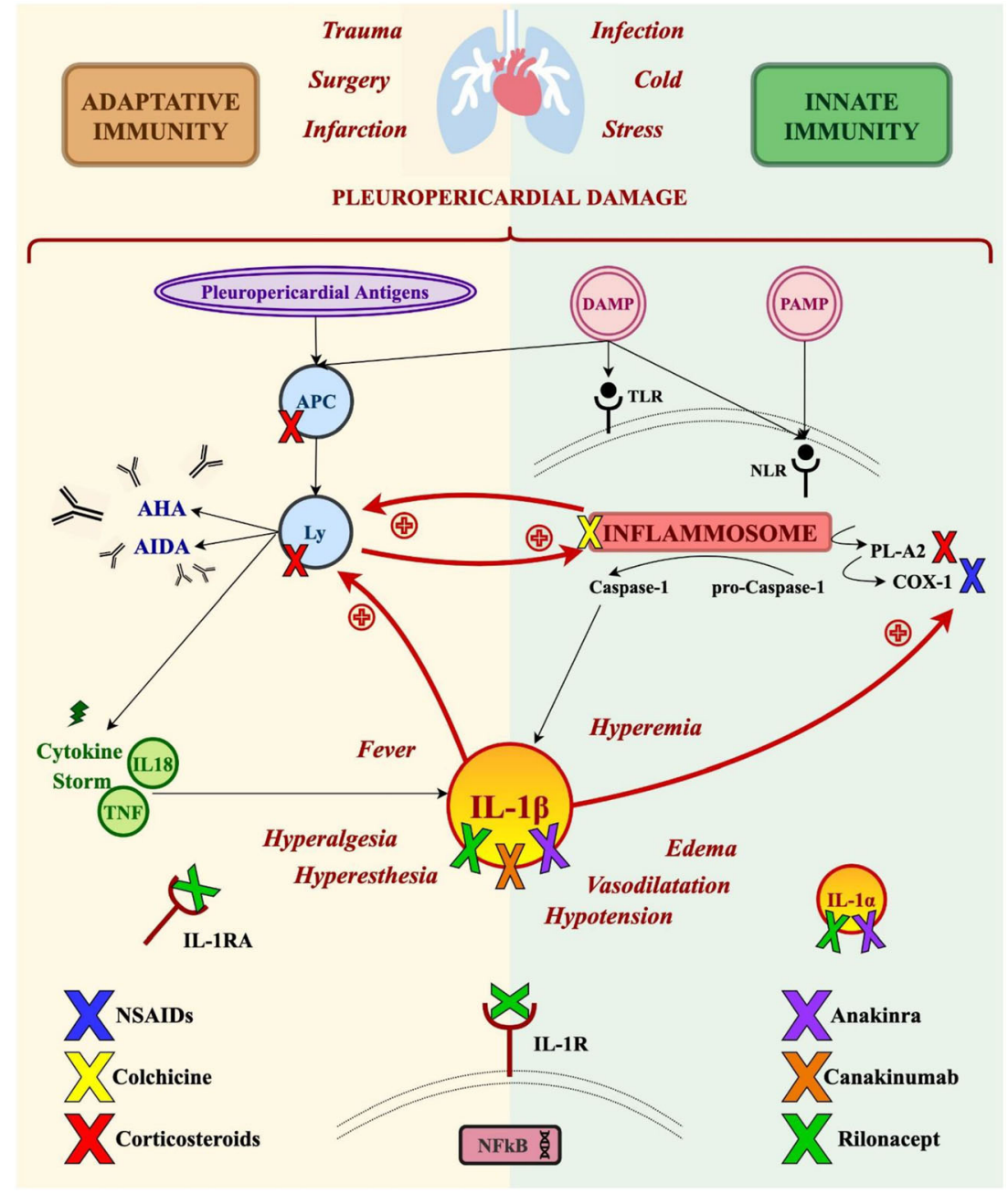

prescribed at the greatest tolerable dosage; severe cases may require IV administration to control pain and a more rapid induction of remission. Colchicine has been proven to be safe and effective in reducing symptoms duration, recurrences, and hospitalization rate [2••, 11-13]. Despite the combination of colchicine and high-dose NSAIDs, recurrences occur in more than $20 \%$ of patients [14]. Low to moderate doses of corticosteroids (e.g., prednisone $0.2-0.5 \mathrm{mg} / \mathrm{kg} \times$ day) can be considered in subjects of incomplete response to NSAIDs and colchicine (triple therapy) or with intolerance/contraindications to NSAIDs (e.g., allergy, pregnancy, bleeding risk) [1••]. Steroid tapering should be very slow to avoid recurrences. Highdose corticosteroids (e.g., prednisone 1 to $1.5 \mathrm{mg} / \mathrm{kg} /$ day) should not be prescribed in IRP because it is suspected to increase the steroid dependency of these patients [12, 15-17]. Lifestyle interventions should overlap pharmacological therapy of IRP but are beyond the scope of this review. Table 1 shows first- and second-line approaches to uncomplicated recurrent pericarditis.

\section{Third-Line Treatment and Novel Immunotherapies}

\section{Immunosuppressive Agents and Intravenous Immunoglobulins}

Since 1987 [14], immunosuppressive agents have been used as third-line therapy for refractory IRP, often in combination with corticosteroids. The most widely used drug is azathioprine at the dose of $2 \mathrm{mg} / \mathrm{kg}$ die $[18,19]$. Azathioprine is a slow-acting corticosteroid-sparing agent that may help in the long term. Little data are available regarding other immunosuppressive agents for RP (e.g., cyclophosphamide, methotrexate, cyclosporine, mycophenolate, and hydroxychloroquine) [18, 20•].

Small case series suggest that intravenous immunoglobulins (IVIGs, $400-500 \mathrm{mg} / \mathrm{kg}$ for 5 days, potentially followed by an additional cycle 1 after 1 month) might be effective in refractory IRP during the acute phase $[21,22]$. Since the advent of anti-IL1 therapies, the role of immunosuppressive agents and IGIV has much reduced, being mostly confined 
Table 1 Standard pharmacological approach to uncomplicated recurrent pericarditis

\begin{tabular}{|c|c|c|c|}
\hline Drug & Initial dose & Tapering & Therapy duration \\
\hline \multicolumn{4}{|c|}{ First-line therapy ${ }^{a}$} \\
\hline \multicolumn{4}{|c|}{ Level of evidence: $A$} \\
\hline Aspirin & $500-1000 \mathrm{mg}$ every $8 \mathrm{~h}(1500-3000 \mathrm{mg}$ daily $)$ & $\begin{array}{l}\text { Following the resolution of symptoms, decrease the total daily dose } \\
\text { by } 250-500 \mathrm{mg} \text { weekly over } 2 \text { to } 4 \text { weeks in an attempt to } \\
\text { reduce the subsequent recurrence rate }\end{array}$ & Weeks-months \\
\hline Ibuprofen & $600-800 \mathrm{mg}$ every $8 \mathrm{~h}(1800-2400 \mathrm{mg}$ daily) & $\begin{array}{l}\text { Following the resolution of symptoms, decrease the total daily dose } \\
\text { by } 200-400 \text { mg weekly for } 2 \text { to } 4 \text { weeks in an attempt to reduce } \\
\text { the subsequent recurrence rate }\end{array}$ & Weeks-months \\
\hline Indomethacin & $25-50 \mathrm{mg}$ every $8 \mathrm{~h}(75-150 \mathrm{mg}$ daily) & $\begin{array}{l}\text { Following the resolution of symptoms, decrease the total daily dose } \\
\text { by } 25 \text { mg weekly for } 2 \text { to } 4 \text { weeks in an attempt to reduce the } \\
\text { subsequent recurrence rate }\end{array}$ & Weeks-months \\
\hline Naproxen** & $\begin{array}{l}250-500 \mathrm{mg} \text { every } 12 \mathrm{~h} \text {; maximal daily dose } \\
1500 \mathrm{mg} \text { for limited time period }(<6 \text { months })\end{array}$ & $\begin{array}{l}\text { Following the resolution of symptoms, decrease the total daily dose } \\
\text { by } 125-250 \mathrm{mg} \text { every } 1-2 \text { week }\end{array}$ & Weeks-months \\
\hline Colchicine & $\begin{array}{l}0.6 \mathrm{mg} \text { twice daily or } 0.6 \mathrm{mg} \text { once daily for patients } \\
<70 \mathrm{~kg} \text { or with chronic kidney disease }\end{array}$ & Gradual tapering off & At least 6 months \\
\hline \multicolumn{4}{|c|}{ Second-line therapy ${ }^{b}$} \\
\hline \multicolumn{4}{|c|}{ Level of evidence: $B$} \\
\hline Prednisone & 0.2 to $0.5 \mathrm{mg} / \mathrm{kg} /$ daily & $\begin{array}{l}\text { After resolution of symptoms and CRP normalization according to } \\
\text { the following schedule: }>50 \mathrm{mg}=10 \mathrm{mg} / \text { day every } 1-2 \text { weeks } \\
25-50 \mathrm{mg}=5-10 \mathrm{mg} / \text { day every } 1-2 \text { weeks } \\
15-25 \mathrm{mg}=2.5 \mathrm{mg} / \text { day every } 2-4 \text { weeks } \\
<15 \mathrm{mg}=1.25-2.5 \mathrm{mg} \text { /day every } 2-6 \text { weeks }\end{array}$ & Months \\
\hline
\end{tabular}

\footnotetext{
${ }^{\text {a }}$ Aspirin or NSAIDS + colchicine

${ }^{\mathrm{b}}$ Low-dose corticosteroids (added at low to moderate doses to aspirin/NSAIDs and colchicine as triple therapy)

*For all drugs: monitoring based on the assessment of blood count, creatinine, transaminases, C-reactive protein, echocardiography

**Dosage expressed as naproxen base; $200 \mathrm{mg}$ naproxen base is equivalent to $220 \mathrm{mg}$ naproxen sodium
}

to RP associated with systemic autoimmune diseases or in some patients IRP with an autoimmune phenotype.

\section{Anti-IL-1 Therapies}

The most striking advances in the last years include the recognition of the impressive results of anti-IL-1 agents for refractory IRP (Table 2). Available IL-1 antagonists include anakinra and canakinumab [1••], while rilonacept is a third molecule currently being studied on IRP patients by a phase 2 trial. These agents are self-administered by patients by a subcutaneous injection.

\section{Anakinra}

Anakinra is a recombinant non-glycosylated homolog of human IL-1 receptor antagonist (IL-1RA) that competitively inhibits IL- $1 \alpha$ and IL- $1 \beta$ binding to the IL-1 receptor. Anakinra has a short half-life (4-6 h), with rapid recovery of immune function and very low risk of severe infections [32]. The most frequent adverse effects are injection-site reactions, which usually occur after the first week and tend to subside by the first month of therapy. No dose adjustment is required based on BMI, age, or gender [33,34]. Plasma clearance of anakinra occurs predominantly via the kidneys. However, no dose adjustment is needed for patients with mild renal impairment $\left(\mathrm{GFR}>50 \mathrm{ml} / \mathrm{min} \times 1.73 \mathrm{~m}^{2}\right)[32]$, whereas dose or schedule adjustment is indicated for patients with severe renal impairment or end-stage renal disease [33]. Although it has been shown that anakinra therapy induces anti-drug antibodies (ADA), this was not associated with any clinically significant effects on PK, efficacy, or safety [35]. Anakinra is well tolerated, with injection site reactions (ISRs) being the most common adverse event; experienced in up to $70 \%$ of patients (however, 95\% of cases are mild to moderate in severity). Clinical experiences indicated that there are two different types of ISRs in relation to injections of anakinra: immediate burning feeling and delayed erythema with pruritus, swelling, and pain [36]. To alleviate the acute burning, it is advised to warm the syringe to room temperature before the injection and to apply a cold pack to the injection site $2-3 \mathrm{~min}$ before and immediately after the injection. The delayed reactions can be mitigated and treated by the application of topical hydrocortisone or anti-histamine cream [36]. In most cases, ISR disappears within 2 months. However, these reactions may impact on adherence to therapy and patients should be informed in advance about these non-severe and transient skin reactions.

Anakinra is contraindicated in patients with known hypersensitivity to $E$. coli-derived proteins or any components of the product. An increased risk of reactivation of latent tuberculosis (LTB) has been described for patients on biologics, 


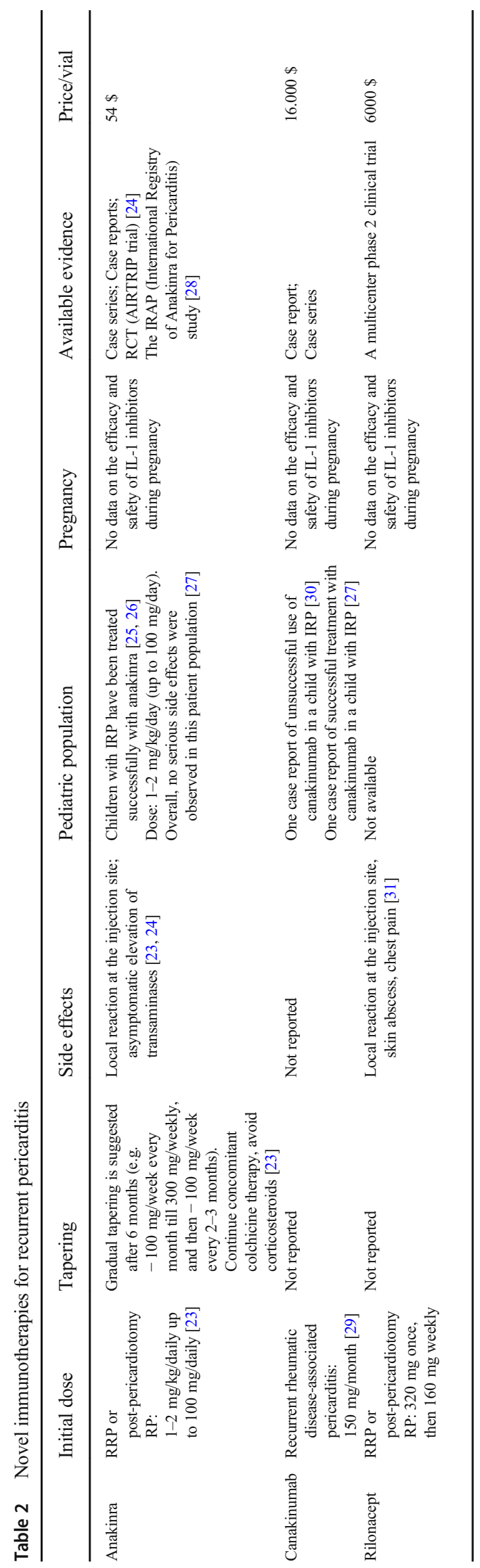

although anakinra and IL1 might confer only moderate risk. However, LTB screening is recommended before beginning therapy and, for some authors, also annually [37]. Clinicians should follow local guidelines at the purpose, such as those provided by the Centers for Disease Control and Prevention (CDC) for screening and prophylaxis of LTB.

Anakinra has been widely used in cardiovascular settings to tackle conditions such as pericardial disease, heart failure, coronary artery disease, and myocardial infarction $[9,24,28$, 38]. After the first reports and case series, anakinra $(100 \mathrm{mg}$ die) was studied in a double-blind, placebo-controlled trial in patients with colchicine-resistant and corticosteroiddependent IRP (the AIRTRIP trial) [39••]. In this study, $90 \%$ of patients treated with conventional agent group faced a relapse vs $18 \%$ in the anakinra group. A recent retrospective study on seven patients with refractory IRP suggests that anakinra is rapidly effective even in corticosteroid-dependent patients with IRP refractory to conventional therapy and also to third-line agents such as AZA and IVIG [28]. A real-life study on an international registry analyzing data from 224 patients with refractory IRP on anakinra showed that anakinra confers a six-fold reduction in recurrences, an 11-fold reduction in ER admissions, and a 7-fold reduction in hospitalizations [40 ${ }^{\bullet}$. Anakinra was generally well tolerated, resulted in lower steroid use and did not associate with serious adverse events: only $3 \%$ of patients discontinued anakinra due to adverse effects. Three patients (14\%) experienced mild and transient transaminase elevation in the AIRTRIP trial [39••] [40•]. In case series of IRP reviewed by Baskar et al., anakinra gave transient transaminase elevation in $10-30 \%$ of patients [41 $]$.

Real-life data [40•] provide insight on IRP recurrences during or after anakinra discontinuation: a higher risk of relapse was seen in patients with a less than a 3-month period on fulldose anakinra treatment before tapering and in those with a tapering scheme shorter than 3 months. The mean time to recurrences increased from 157 days to almost 1000 days in patients on anakinra, implying great disease control and less indirect costs (hospitalizations, school/work absence, steroid side effects management) [40•]. We suggest to follow a very slow tapering of anakinra by progressively discontinuing drug administration in individual days. In the case of relapses during tapering, we maintain the lowest effective dose.

In conclusion, anakinra is safe and effective for refractory IRP, especially in the case of an autoinflammatory phenotype [8, 42].

\section{Canakinumab}

Canakinumab is a human monoclonal antibody anti-IL-1 $\beta$. It has a long half-life of $\sim 22-26$ days and can be administered every 4-8 weeks. After correction for body weight, no clinically significant disease status, gender, or age-related 
differences in pharmacokinetics were observed among patients affected by various inflammatory diseases. Therefore, a fixed dosage of $150 \mathrm{mg} / \mathrm{month}$ is prescribed to adult patients.

A pilot study in 2017 proved canakinumab efficacy in reducing cardiovascular events in secondary prevention [43]. Moreover, canakinumab is the only IL-1 inhibitor approved for the treatment of various autoinflammatory diseases (colchicine-resistant FMF, TRAPS, cryopyrin-associated periodic syndrome [CAPS], and gouty arthritis) and in systemic-onset juvenile idiopathic arthritis (so-JIA) [27, 29, 44]. Canakinumab has limited use in pericarditis due to very high costs is limited to case report and series [45]. A case series on patients with IRP experiencing injection-site reactions to anakinra suggested the efficacy of canakinumab [46]. In another report of a pediatric patient suffering from IRP, canakinumab was effective in controlling disease recurrences, although an anaphylactic reaction occurred [47]. In conclusion, canakinumab might be considered in subjects allergic or intolerant to anakinra, although its cost is very high.

\section{Rilonacept}

Rilonacept, known as "IL-1 trap," is a dimeric fusion protein consisting of the ligand-binding domains of IL-1R and IL-1 receptor accessory protein (IL-1RAP) linked in-line to the Fc portion of human IgG1. Consequently, rilonacept binds to and blocks the activity of IL- $1 \alpha$ and IL- $1 \beta$. Rilonacept also binds the endogenous IL-1RA but with a lower affinity than IL- $1 \beta$ or IL- $1 \alpha$. Based on limited data, steady-state trough concentrations were similar between male and female patients, and scarcely affected by age and body weight. Thus, rilonacept is prescribed at the fixed dose of $160 \mathrm{mg}$ per week by subcutaneous administration. Impaired liver and renal function do not affect pharmacokinetics in a clinically significant way [48]. ADA were detected in $35 \%$ of patients, although there was no correlation of antibody activity with either clinical efficacy or safety. Rilonacept was generally well tolerated. The most common adverse events were mild injection site reactions; however, a transient skin abscess resulting in rilonacept discontinuation has been reported in one patient (4\%), in a multicenter Phase 2 Clinical Trial enrolling 25 adults with RP [49•]. Rilonacept has been given the "orphan drug" status by the FDA for the treatment of CAPS, since it grants significant improvement of symptoms and normalization of serum amyloid A (SAA) levels with good safety and tolerability profile [25, 31]. Also, it has been successfully tested in the prevention of gout flares, but the FDA rejected its enlistment among gout drugs for lack of long-term safety and efficacy data and economic sustainability [50]. A RCT proved its efficacy in systemic-onset juvenile idiopathic arthritis [51]. In 2019, the FDA granted rilonacept the "Breakthrough Therapy" status, based on results from an open-label phase 2 trial that provided the first evidence of rilonacept efficacy and safety in IRP patients [49•]. The authors reported a reduction of recurrences, lower steroid requirements, and improved life quality in all types of patients, ranging from symptomatic IRP to asymptomatic corticosteroid-dependent IRP. Patients belonging to the first category reported a reduction both in pain, inflammation, and pericardial signs of pericarditis, whereas all patients on corticosteroids stopped them without experiencing relapses during the 18 extension weeks. Adverse events occurred in 13 subjects (9/13 drug-related), most commonly mild transient injection site reactions (no discontinuations) [49•].

Currently, rilonacept is now under investigation in phase 3 clinical trial RHAPSODY (NCT03737110), in IRP patients with at least three pericarditis recurrences while receiving any combination of first- and secondline therapy. In the RHAPSODY trial, a single-blinded period of rilonacept administration (320 mg loading dose and $160 \mathrm{mg}$ sc weekly, with concomitant tapering of other therapies) is followed by a double-blinded withdrawal randomization in either rilonacept or placebo for 24 weeks. This study is estimated to be completed by June 2021 .

\section{Comparing Anakinra, Canakinumab, and Rilonacept}

According to available data, efficacy and safety profiles of anakinra, canakinumab, and rilonacept seem similar. All of these three agents require subcutaneous administration. The short half-life of anakinra results in daily subcutaneous administration and a higher potential safety in the case of concomitant serious infection. Rilonacept requires weekly administrations while canakinumab only once a month. In the IRP setting, anakinra is the only drug with supporting evidence coming from randomized clinical trials. To date, there is no evidence that selective antagonism of IL-1 $\beta$ might be less effective and safer than unselective antagonism of IL- $1 \alpha$ and IL- $1 \beta$. However, some experts have suggested that blocking both IL- $1 \alpha$ and IL- $1 \beta$ might be useful in severe cases; on the other hand, it is reasonable to expect a better compliance in patients treated with canakinumab due to easier administration schedule.

While NSAIDs, colchicine and steroids are very cheap, a disadvantage of anti-IL therapy is high cost: canakinumab is the least affordable of these drugs, while anakinra is the cheapest (with an ex-factory price of about $930 € / 1060 \$$ per month). To date, there are no cost-effectiveness data of anti-IL1 agents as compared to traditional therapy in IRP. Thus, we suggest to limit their prescription to cases in which first- and secondline agents result in suboptimal disease control. 


\section{Specific Clinical Settings}

\section{Pediatric Population}

About $5 \%$ of chest pain in children (mostly male adolescents) is caused by pericarditis $[52 \bullet, 53]$. The autoinflammatory phenotype of pediatric pericarditis is more frequent than in adult patients. Since specific etiologies are more frequent in children suffering from RP, a genetic screening for FMF or TRAPS is often proposed in case of periodic fever history or familiarity for RP or autoinflammatory disorders [4•]. Very little specific evidence is available for pediatric patients. Regarding traditional therapy, ASA is not recommended in order to avoid Reye syndrome. Corticosteroids should be avoided as much as possible due to its side effects (e.g., growth retardation, pediatric obesity) $[1 \bullet \bullet, 15,54-56]$. Regarding anti-IL1 agents, the long-term use of anakinra in monotherapy was associated with persistent control of RP in 12 children enrolled in a multicenter retrospective study by Finetti et al. [57]. In line with this, a pediatric case of steroiddependent RP, with a dramatic therapeutic response to anakinra but without response to canakinumab has been recently reported [58]. Given anakinra safety and efficacy in children with autoinflammatory diseases and in pediatric case series of refractory IRP $[39,59 \bullet, 60]$, it might be rational to use anakinra earlier than in adult patients (e.g., as a second-line therapy or after a lower number or relapses). Anakinra doses require adjustments in these patients (see Table 2).

\section{Pregnancy}

Pericardial diseases during pregnancy are rare and little evidence is available for this setting. Observational studies have reported a good outcome for women and infants [61•]. NSAIDs require a gradual tapering until gestational week 20 , due to the increased risk of constriction of the ductus arteriosus and impaired fetal renal function; NSAIDs must be stopped before gestational week 32 [62]. Prednisone, prednisolone, and methylprednisolone may be used during all pregnancy at low-dose since they are metabolized by the placenta into inactive forms [62]. Low-dose colchicine has been safely used in women with FMF during pregnancy and breastfeeding, and it can be suggested also in RP pregnant patients $[61 \bullet, 63]$. Little evidence is available about anakinra safety during pregnancy and lactation. The current recommendation is to discontinue this medication prior to pregnancy given the lack of safety evidence [63] and to discontinue breast-feeding during treatment with anakinra [64]. However, IL-RA is a normal component of human milk and a small retrospective series documented positive maternal and fetal outcomes of 43 pregnancies maternally exposed to antiIL1 agents.

\section{Post-Cardiac Injury Syndromes}

Post-cardiac injury syndromes include pleuro-pericarditis occurring after myocardial infarction, chest trauma, cardiac surgery, and percutaneous procedures. Once elicited, pleuropericarditis can be monophasic or recurrent. Pathogenesis is poorly understood, although it is likely to include autoinflammation and autoimmunity similarly to IRP [65]. Accordingly, post-cardiac injury recurrent pericarditis can be management similarly to IRP, as recently reviewed by Verma et al. [65].

\section{Autoimmune Diseases}

Cardiac involvement is very common in autoimmune disorders such as SLE, RA, SS, Still disease, rheumatic polymyalgia, and vasculitis (e.g., Behcet's disease, giant cell arteritis, Takayasu arteritis) [66-69]. Pericarditis relapses often overlap with flares of the underlying condition, which represent the main focus of therapy. In some cases, RP represents the main clinical feature and it may be less clear whether therapy should focus on RP or follow the standard of care for the underlying condition, considering pericarditis as an epiphenomenon. It is reasonable to assume that the correct approach lies in the middle, but nowadays, there is no consensus about any therapeutic algorithm. As a general indication, NSAIDS, colchicine, and corticosteroids might be used for acute management of pericarditis unless contraindicated, although immunosuppressive agents are typically required $[1 \bullet$, 23, 70-73]. Anti-IL-1 immunotherapies must be carefully considered in these patients. However, IL-6 signaling blockade by tocilizumab has been used in many autoimmune conditions such as RA, adult-onset Still disease, Takayasu arteritis, and associated concomitant RP [23, 26, 30, 74, 75]. Interestingly, Lee et al. investigated whether anakinra could block Lactobacillus casei cell wall extract (LCWE)-induced coronary lesions, in an established mouse model of Kawasaki disease (KD) [76]. They found that these lesions can efficiently be prevented by anakinra, providing both innovative cellular and molecular mechanistic insights and novel therapeutic strategies to prevent the development of coronary lesions. Furthermore, anakinra was effective in a patient with fulminant viral myocarditis, suggesting that anakinra may represent a promising candidate for the treatment of inflammatory heart failure [77].

\section{Autoinflammatory Diseases}

$\mathrm{RP}$ is frequent in many autoinflammatory diseases, including FMF and TRAPS. RP in these patients should be considered as a red flag for poorly controlled disease and treated accordingly: FMF patients should be managed with up-titration of colchicine or with anti-IL1 therapies [78], while TRAPS patients should be offered biologic therapy [79]. 


\section{Other Possible Biological Therapies}

IL-6 is another pivotal inflammatory cytokine. High levels of IL- 6 have been demonstrated in the pericardial fluid compared to serum, suggesting that IL-6 is locally produced and might concur in driving pericardial inflammation. Their subjects have been reported to be successfully treated with tocilizumab for refractory pericardial effusions with RA and a further patient for refractory SLE-associated pericarditis [80-82]. A recent case of successful treatment of SLE-associated pleuritis with tocilizumab was also reported [83]. Further studies are required to assess whether IL-6 might have a role in IRP.

Myopericarditis has been described in the current pandemic of coronavirus disease 2019 (COVID-19) [84]. Severe COVID-19 is characterized by hyperinflammation potentially due to a cytokine storm syndrome [85]. Randomized clinical trials, such as the AMMURAVID trial, are ongoing to verify anti-cytokine agents blocking IL-1 and IL-6 might be effective also in this condition.

\section{Conclusions}

IRP has primarily an autoinflammatory and/or autoimmune etiology. Management is based on high-dose NSAIDs and colchicine and low to moderate dose of corticosteroids in the case of suboptimal disease control. The IL-1 pathway has emerged as pivotal in the pathogenesis of IRP, and anti-IL-1 agents have been proven to be highly effective in patients with refractory IRP and autoinflammatory features.

Future studies should clarify the optimal duration and tapering schedule of treatment with these agents. Moreover, biomarker studies would be required to understand which patients will experience refractory disease requiring anti-IL-1 therapy and which others will suffer from recurrences during the tapering of these agents, in order to allow a more efficient and personalized therapy. Lastly, most of the recent advances have involved patients with highly inflammatory RP. Future studies should focus also on the subjects with the autoimmune or the pauciinflammatory phenotype of IRP.

\section{Compliance with Ethical Standards}

Conflict of Interest Prof Brucato discloses unrestricted research grants by SOBI and SOBI e ACARPIA. All other authors have no conflict of interest to disclose.

Human and Animal Rights and Informed Consent This article does not contain any studies with human or animal subjects performed by any of the authors.
Abbreviations $A D A$, Anti-drug antibodies; $A H A$, Anti-heart antibodies; $A I D A$, Anti-intercalated disk autoantibodies; $A N A$, Anti-nuclear antibodies; $A S A$, Acetylsalicylic acid; CAPS, Cryopyrin-associated periodic syndrome; $C O X-2$, Cyclo-oxygenase-2; $C R P$, C-reactive protein; DAMPs, Damage-associated molecular patterns (DAMPs); ESC, European Society of Cardiology; $F M F$, Familial Mediterranean fever; GFR, Glomerula filtration rate; $I L-1$, Interleukin-1; $I L-1 R$, IL-1 receptor; $I L$ $1 R A$, IL-1 receptor antagonist; IL-1RAcP, IL-1 receptor accessory protein; $I L-1 \beta A$, IL-1 $\beta$ antagonist; IRP, Idiopathic recurrent pericarditis (IRP); IVIGs, Human intravenous immunoglobulins; NSAIDs, Non-steroidal anti-inflammatory drugs; $P A M P S$, Pathogen-associated molecular patterns (PAMPs); $P G$, Prostaglandins; $P K$, Pharmacokinetics; $Q o L$, Quality of life; $R A$, Rheumatoid arthritis; $R P$, Recurrent pericarditis; $S A A$, Serum amyloid A; SJIA, Systemic juvenile idiopathic arthritis; $S L E$, Systemic lupus erythematosus; SS, Sjogren's syndrome; TB, Tuberculosis; TRAPS, Tumor necrosis factor receptor-associated periodic syndrome

\section{References}

Papers of particular interest, published recently, have been highlighted as:

- Of importance

• Of major importance

1.• Adler Y, Charron P, Imazio M, Badano L, Barón-Esquivias G, Bogaert J, et al. 2015 ESC guidelines for the diagnosis and management of pericardial diseases. Eur Heart J. 2015;36(42):2921-64. https://doi.org/10.1093/eurheartj/ehv318. 2015 ESC Guidelines summarize and evaluate all available evidence on pericardial diseases, with the aim of assisting health professionals in selecting the best management strategies for the diagnosis and management of these clinical conditions.

2.• Lu YY, Chen YJ. A randomized trial of colchicine for acute pericarditis. N Engl J Med. 2014;370(8):780. https://doi.org/10.1056/ NEJMc1315351. Th Authors discussed findings from a randomized trial of colchicine for acute pericarditis.

3. Cremer PC, Kumar A, Kontzias A, Tan CD, Rodriguez ER, Imazio $\mathrm{M}$, et al. Complicated Pericarditis: Understanding risk factors and pathophysiology to inform imaging and treatment. J Am Coll Cardiol. 2016;68(21):2311-28.

4. Tombetti E, Giani T, Brucato A, Cimaz R. Recurrent pericarditis in children and adolescents. Front Pediatr. 2019;7(October):419. https://doi.org/10.3389/fped.2019.00419. The Authors reviewed the etiopathogenesis, diagnosis and management of RP in pediatric patients.

5. Brucato A, Imazio M, Cremer PC, Adler Y, Maisch B, Lazaros G, et al. Recurrent pericarditis: still idiopathic? The pros and cons of a well-honoured term. Intern Emerg Med. 2018;13(6):839-44. https://doi.org/10.1007/s11739-018-1907-x. The Authors discussed the pros and cons of using the term "idiopathic" in light of the new knowledge.

6. March CJ, Mosley B, Larsen A, Cerretti DP, Braedt G, Price V, et al. Cloning, sequence and expression of two distinct human interleukin-1 complementary DNAs. Nature. 1985;315(6021): 641-7. https://doi.org/10.1038/315641a0.

7. Gery I, Gershon RK, Waksman BH. Potentiation of the Tlvmphocyte response to mitogens: I. The responding cell. J Exp Med. 1972;136(1):128-42. https://doi.org/10.1084/jem.136.1.128.

8. Dinarello CA, Anna S, van der Meer J. Treating inflammation by blocking interleukin-1 in a broad spectrum of diseases. Nat Rev 
Drug Discov. 2012;11(8):633-52. https://doi.org/10.1038/ $\operatorname{nrd} 3800$.

9. Abbate A, Trankle CR, Buckley LF, Lipinski MJ, Appleton D, Kadariya D, et al. Interleukin-1 blockade inhibits the acute inflammatory response in patients with st-segment-elevation myocardial infarction. J Am Heart Assoc. 2020;9(5):e014941. https://doi.org/ 10.1161/JAHA.119.014941 [ePub ahead of print].

10. Imazio M, Brucato A, Mayosi BM, Derosa FG, Lestuzzi C, MacOr A, et al. Medical therapy of pericardial diseases: part I: idiopathic and infectious pericarditis. J Cardiovasc Med. 2010;11(10):712-22. https://doi.org/10.2459/JCM.0b013e3283340b97.

11. Agarwal SK, Vallurupalli S, Uretsky BF, Hakeem A. Effectiveness of colchicine for the prevention of recurrent pericarditis and postpericardiotomy syndrome: an updated meta-analysis of randomized clinical data. Eur Hear J Cardiovasc Pharmacother. 2015;1(2):11725. https://doi.org/10.1093/ehjcvp/pvv001.

12. Imazio M, Bobbio M, Cecchi E, Demarie D, Pomari F, Moratti M, et al. Colchicine as first-choice therapy for recurrent pericarditis: results of the CORE (COlchicine for REcurrent pericarditis) trial. Arch Intern Med. 2005;165(17):1987-91. https://doi.org/10.1001/ archinte.165.17.1987.

13. Imazio M, Brucato A, Cemin R, Ferrua S, Belli R, Maestroni S, et al. Colchicine for recurrent pericarditis (CORP): a randomized trial. [Summary for patients in Ann Intern Med. 2011 Oct 4;155(7): I28; PMID: 21873706]. Ann Intern Med. 2011;155(7):409-14.

14. Schwier N, Hale G, Davies M. Treatment of adults with idiopathic recurrent pericarditis: novel use of immunotherapy. Pharmacotherapy. 2017;38(1):42-9. https://doi.org/10.1111/ijlh. 12426.

15. Artom G, Koren-Morag N, Spodick DH, Brucato A, Guindo J, Bayes-de-Luna A, et al. Pretreatment with corticosteroids attenuates the efficacy of colchicine in preventing recurrent pericarditis: a multi-centre all-case analysis. Eur Heart J. 2005;26(7):723-7. https://doi.org/10.1093/eurheartj/ehi197.

16. KILBOURNE ED, WILSON CB, PERRIER D. The induction of gross myocardial lesions by a Coxsackie (pleurodynia) virus and cortisone. J Clin Invest. 1956;35(4):362-70. https://doi.org/10. 1172/JCI103286.

17. Imazio M, Brucato A, Cumetti D, Brambilla G, Demichelis B, Ferro S, et al. Corticosteroids for recurrent pericarditis: high versus low doses: a nonrandomized observation. Circulation. 2008;118(6): 667-71. https://doi.org/10.1161/CIRCULATIONAHA.107. 761064.

18. Peiffer-Smadja N, Domont F, Saadoun D, Cacoub P. Corticosteroids and immunosuppressive agents for idiopathic recurrent pericarditis. Autoimmun Rev. 2019;18(6):621-6. https:// doi.org/10.1016/j.autrev.2019.04.001.

19. Vianello F, Cinetto F, Cavraro M, Battisti A, Castelli M, Imbergamo S, et al. Azathioprine in isolated recurrent pericarditis: a single centre experience. Int J Cardiol. 2011;147(3):477-8. https://doi.org/10.1016/j.ijcard.2011.01.027.

20. Chiabrando JG, Bonaventura A, Vecchié A, Wohlford GF, Mauro AG, Jordan JH, et al. Management of acute and recurrent pericarditis: JACC state-of-the-art review. J Am Coll Cardiol. 2020;75(1): 76-92. https://doi.org/10.1016/j.jacc.2019.11.021. The Authors summarize the up-to-date management of acute and recurrent pericarditis.

21. Imazio M, Lazaros G, Picardi E, Vasileiou P, Carraro M, Tousoulis $\mathrm{D}$, et al. Intravenous human immunoglobulins for refractory recurrent pericarditis: a systematic review of all published cases. J Cardiovasc Med (Hagerstown). 2016;17(4):263-9. https://doi.org/ 10.2459/JCM.0000000000000260.

22. Maisch B, Rupp H, Ristic A, Pankuweit S. Pericardioscopy and epiand pericardial biopsy - a new window to the heart improving etiological diagnoses and permitting targeted intrapericardial therapy.
Heart Fail Rev. 2013;18(3):317-28. https://doi.org/10.1007/ s10741-013-9382-y.

23. Tombetti E, Mason JC. Takayasu arteritis: advanced understanding is leading to new horizons. Rheumatology. 2019;58(2):206-19. https://doi.org/10.1093/rheumatology/key040.

24. Biondi-Zoccai G, Garmenda CM, Abbate A, Giordano A, Frati G, Sciarretta $\mathrm{S}$, et al. Atherothrombosis prevention and treatment with anti-interleukin-1 agents. Curr Atheroscler Rep. 2020;22(1):4. https://doi.org/10.1007/s11883-020-0819-1.

25. Hoffman HM, Throne ML, Amar NJ, Cartwright RC, Kivitz AJ, Soo Y, et al. Long-term efficacy and safety profile of rilonacept in the treatment of cryopryin-associated periodic syndromes: results of a 72-week open-label extension study. Clin Ther. 2012;34(10): 2091-103. https://doi.org/10.1016/j.clinthera.2012.09.009.

26. Tombetti E, Di Chio MC, Sartorelli S, Bozzolo E, Sabbadini MG, Manfredi AA, et al. DCMC. Anti-cytokine treatment for Takayasu arteritis: state of the art. Intractable Rare Dis Res. 2014;3(1):29-33. https://doi.org/10.5582/irdr.3.29.

27. Ruperto N, Brunner HI, Quartier P, Constantin T, Wulffraat N, Horneff $\mathrm{G}$, et al. Two randomized trials of canakinumab in systemic juvenile idiopathic arthritis for the PRINTO and PRCSG*. N Engl J Med. 2012;367:2396-406. https://doi.org/10.1056/ NEJMoa1205099.

28. Dagan A, Langevitz P, Shoenfeld Y, Shovman O. Anakinra in idiopathic recurrent pericarditis refractory to immunosuppressive therapy: a preliminary experience in seven patients. Autoimmun Rev. 2019;18(6):627-31. https://doi.org/10.1016/j.autrev.2019.01. 005 .

29. De Benedetti F, Gattorno M, Anton J, Eldad BC, Frenkel J, Hoffman HM, et al. Canakinumab for the treatment of autoinflammatory recurrent fever syndromes. N Engl J Med. 2018;378(20):1908-19. https://doi.org/10.1056/NEJMoa1706314.

30. Tombetti E, Franchini S, Papa M, Sabbadini MG, Baldissera E. Treatment of refractory Takayasu arteritis with tocilizumab: 7 Italian patients from a single referral center. J Rheumatol. 2013;40(12):2047-51. https://doi.org/10.3899/jrheum.130536.

31. Hoffman HM, Throne ML, Amar NJ, Sebai M, Kivitz AJ, Kavanaugh A, et al. Efficacy and safety of rilonacept (interleukin-1 trap) in patients with cryopyrin-associated periodic syndromes: results from two sequential placebo-controlled studies. Arthritis Rheum. 2008;58(8):2443-52. https://doi.org/10.1002/art. 23687.

32. Boiten W. Annex I. Hydrometry. 2003;1-35. https://doi.org/10. 1201/9780203971093.bmatt.

33. Yang BB, Baughma S, Sullivan J. Pharmacokinetics of anakinra in subjects with different levels of renal function. Clin Pharmacol Ther. 2003;70(4):1262-79. https://doi.org/10.1002/hep.30657.

34. Yang BB, Gozzi P, Sullivan JT. Pharmacokinetics of anakinra in subjects of heavier vs. lighter body weights. Clin Transl Sci. 2019;12(4):371-8. https://doi.org/10.1111/cts.12622.

35. Wikén M, Hallén B, Kullenberg T, Koskinen LO. Development and effect of antibodies to anakinra during treatment of severe CAPS: sub-analysis of a long-term safety and efficacy study. Clin Rheumatol. 2018;37(12):3381-6. https://doi.org/10.1007/s10067018-4196-x.

36. Kaiser C, Knight A, Nordström D, Pettersson T, Fransson J, FlorinRobertsson E, et al. Injection-site reactions upon Kineret (anakinra) administration: experiences and explanations. Rheumatol Int. 2012;32(2):295-9.

37. Goletti D, Petrone L, Ippolito G, Niccoli L, Nannini C, Cantini F. Preventive therapy for tuberculosis in rheumatological patients undergoing therapy with biological drugs. Expert Rev Anti-Infect Ther. 2018;16(6):501-12.

38. Emmi G, Urban ML, Imazio M, Gattorno M, Maestroni S, Lopalco $\mathrm{G}$, et al. Use of interleukin-1 blockers in pericardial and cardiovascular diseases. Curr Cardiol Rep. 2018;20(8):61. 
39.• Brucato A, Imazio M, Gattorno M, Lazaros G, Maestroni S, Carraro $\mathrm{M}$, et al. Effect of anakinra on recurrent pericarditis among patients with colchicine resistance and corticosteroid dependence: the AIRTRIP randomized clinical trial. JAMA. 2016;316(18):190612. https://doi.org/10.1001/jama.2016.15826. This is the first randomized clinical trial aimed at assessing the efficacy of anakinra for refractory idiopathic recurrent pericarditis with corticosteroid dependence and after failure of colchicine therapy.

40. Imazio M, Andreis A, De Ferrari GM, Cremer PC, Mardigyan V, Maestroni S, Luis SA, Lopalco G, Emmi G, Lotan D, et al. Anakinra for corticosteroid-dependent and colchicine-resistant pericarditis: the IRAP (International Registry of Anakinra for Pericarditis) study. Eur J Prev Cardiol. 2019. https://doi.org/10. 1177/2047487319879534. The authors discussed findings from the first international registry on the use of anakinra in patients with corticosteroid-dependent and colchicine-resistant refractory $R P$.

41. Baskar S, Klein AL, Zeft A. The use of IL-1 receptor antagonist (anakinra) in idiopathic recurrent pericarditis: a narrative review. Cardiol Res Pract. 2016;2016:7840724. The Authors summarize the current understanding of the etiopathogenesis of idiopathic recurrent pericarditis, mechanism of action of anakinra, and the preliminary evidence.

42. Parizo JT, Moayedi Y, Nieman K, Town K, Teuteberg JJ, Khush KK. A novel therapy for an unusual problem: IL-1 receptor antagonist for recurrent post-transplant pericarditis. Clin Transpl. 2019;33(10):e13699. https://doi.org/10.1111/ctr.13699.

43. Ridker PM, Everett BM, Thuren T, MacFadyen JG, Chang WH, Ballantyne C, et al. Antiinflammatory therapy with canakinumab for atherosclerotic disease. N Engl J Med. 2017;377(12):1119-31. https://doi.org/10.1056/NEJMoa1707914.

44. Sąhin A, Derin ME, Albayrak F, Karakaş B, Karagöz Y. Assessment of effectiveness of anakinra and canakinumab in patients with colchicine-resistant/unresponsive familial Mediterranean fever. Adv Rheumatol. 2020;60(1):1-7. https:// doi.org/10.1186/s42358-020-0117-1

45. Lazaros G, Antonatou K, Vassilopoulos D. The therapeutic role of interleukin-1 inhibition in idiopathic recurrent pericarditis: current evidence and future challenges. Front Med. 2017;4(JUN):1-6. https://doi.org/10.3389/fmed.2017.00078.

46. Kougkas N, Fanouriakis A, Papalopoulos I, Bertsias G, Avgoustidis N, Repa A, et al. Canakinumab for recurrent rheumatic disease associated-pericarditis: a case series with long-term follow-up. Rheumatology (Oxford). 2018;57(8):1494-5. https://doi. org/10.1093/rheumatology/key077.

47. Epçaçan S, Sahin S, Kasapcopur O. Anaphylactic reaction to anakinra in a child with steroid-dependent idiopathic recurrent pericarditis and successful management with canakinumab. Cardiol Young. 2019;29(4):549-51. https://doi.org/10.1017/ S1047951119000672

48. Radin A, Marbury T, Osgood G, Belomestnov P. Safety and pharmacokinetics of subcutaneously administered rilonacept in patients with well-controlled end-stage renal disease (ESRD). J Clin Pharmacol. 2010;50(7):835-41. https://doi.org/10.1177/ 0091270009351882

49. Klein A, Lin D, Cremer P, Nasir S, Crugnale S, Collins L, et al. Rilonacept in recurrent pericarditis: first efficacy and safety data from an ongoing phase 2 pilot clinical trial. J Am Coll Cardiol. 2019;73(9):1261. https://doi.org/10.1016/s0735-1097(19)31868-6. The authors discussed preliminary safety and efficacy data on rilonacept in recurrent Pericarditis from an Ongoing Phase 2 Pilot Clinical Trial.

50. Mitha E, Ralph Schumacher H, Fouche L, Luo SF, Weinstein SP, Yancopoulos GD, et al. Rilonacept for gout flare prevention during initiation of uric acid-lowering therapy: results from the
PRESURGE-2 international, phase 3, randomized, placebocontrolled trial. Rheumatology (Oxford). 2013;52(7):1285-92. https://doi.org/10.1093/rheumatology/ket114.

51. Ilowite NT, Prather K, Lokhnygina Y, Schanberg LE, Elder M, Milojevic D, et al. Randomized, double-blind, placebo-controlled trial of the efficacy and safety of rilonacept in the treatment of systemic juvenile idiopathic arthritis. Arthritis Rheum. 2014;66(9):2570-9. https://doi.org/10.1002/art.38699.

52. Imazio M, Brucato A, Pluymaekers N, Breda L, Calabri G, Cantarini L, et al. Recurrent pericarditis in children and adolescents: a multicentre cohort study. J Cardiovasc Med. 2016;17(9): 707-12. https://doi.org/10.2459/JCM.0000000000000300. The Authors discussed findings from a multicenter cohort study of 110 consecutive cases of paediatric patients with at least two recurrences of pericarditis over an 11-year period.

53. Shakti D, Hehn R, Gauvreau K, Sundel RP, Newburger JW. Idiopathic pericarditis and pericardial effusion in children: contemporary epidemiology and management. J Am Heart Assoc. 2014;3(6):e001483. https://doi.org/10.1161/JAHA.114.001483.

54. Imazio M, Brucato A, Maestroni S, Cumetti D, Dominelli A, Natale G, et al. Prevalence of C-reactive protein elevation and time course of normalization in acute pericarditis: implications for the diagnosis, therapy, and prognosis of pericarditis. Circulation. 2011;123(10):1092-7. https://doi.org/10.1161/CIRCULATIONAHA.110.986372.

55. Adler Y, Shoenfeld Y. Colchicine as therapy for recurrent pericarditis. Harefuah. 1997;133(3-4):100-2.

56. Raatikka M, Pelkonen PM, Karjalainen J, Jokinen EV. Recurrent pericarditis in children and adolescents: report of 15 cases. J Am Coll Cardiol. 2003;42(4):759-64.

57. Finetti M, Insalaco A, Cantarini L, Meini A, Breda L, Alessio M, et al. Long-term efficacy of interleukin-1 receptor antagonist (anakinra) in corticosteroid-dependent and colchicine-resistant recurrent pericarditis. J Pediatr. 2014;164(6):1425-1431.e1. https:// doi.org/10.1016/j.jpeds.2014.01.065.

58. Theodoropoulou K, von Scheven-Gête A, Bressieux-Degueldre S, Prsa M, Angelini F, Boulos T, et al. A case of corticosteroiddependent recurrent pericarditis with different response to two IL1 blocking agents. Pediatr Rheumatol. 2015;13(S1):P155. https:// doi.org/10.1186/1546-0096-13-s1-p155.

59. Picco P, Brisca G, Traverso F, Loy A, Gattorno M, Martini A. Successful treatment of idiopathic recurrent pericarditis in children with interleukin-1beta receptor antagonist (anakinra): an unrecognized autoinflammatory disease? Arthritis Rheum. 2009;60(1): 264-8. https://doi.org/10.1002/art.24174. The Authors reported three cases of children with recurrent pericarditis who were treated with anakinra, with immediate response and discussed similarities between idiopathic recurrent pericarditis and autoinflammatory diseases.

60. Brucato A, Emmi G, Cantarini L, Di Lenarda A, Gattorno M, Lopalco G, et al. Management of idiopathic recurrent pericarditis in adults and in children: a role for IL-1 receptor antagonism. Intern Emerg Med. 2018;13(4):475-89. https://doi.org/10.1007/s11739018-1842-x.

61. Brucato A, Pluymaekers N, Tombetti E, Rampello S, Maestroni S, Lucianetti M, et al. Management of idiopathic recurrent pericarditis during pregnancy. Int J Cardiol. 2019;282:60-5. https://doi.org/10. 1016/j.ijcard.2019.02.003. The Authors evaluated the management and outcome of idiopathic recurrent pericarditis during pregnancy.

62. Brucato A, Imazio M, Curri S, Palmieri G, Trinchero R. Medical treatment of pericarditis during pregnancy. Int $\mathrm{J}$ Cardiol. 2010;144(3):413-4. https://doi.org/10.1016/j.ijcard.2009.03.028.

63. Götestam Skorpen C, Hoeltzenbein M, Tincani A, Fischer-Betz R, Elefant E, Chambers $\mathrm{C}$, et al. The EULAR points to consider for use of antirheumatic drugs before pregnancy, and during pregnancy and 
lactation. Ann Rheum Dis. 2016;75(5):795-810. https://doi.org/10. 1136/annrheumdis-2015-208840.

64. Smith CJF, Chambers CD. Five successful pregnancies with antenatal anakinra exposure. Rheumatology (Oxford). 2018;57(7): 1271-5. https://doi.org/10.1093/rheumatology/key093.

65. Verma BR, Chetrit M, Gentry JL, Noll A, Bafadel A, Khayata M, et al. Multimodality imaging in patients with post-cardiac injury syndrome. Heart. 2020;106(9):639-46.

66. Guillaume MP, Vachiery F, Cogan E. Pericarditis: an unusual manifestation of giant cell arteritis. Am J Med. 1991;91(6):662-4. https://doi.org/10.1016/0002-9343(91)90223-K.

67. Baldini C, Talarico R, Della Rossa A, Bombardieri S. Clinical manifestations and treatment of Churg-Strauss syndrome. Rheum Dis Clin N Am. 2010;6(3):527-43.

68. Grant SCD, Levy RD, Venning MC, Ward C, Brooks NH. Wegener's granulomatosis and the heart. Br Heart J. 1994;71(1): 82-6. https://doi.org/10.1136/hrt.71.1.82.

69. Tombetti E, Mason JC. Application of imaging techniques for Takayasu arteritis. Presse Med. In press.

70. Imazio M, Brucato A, Doria A, Brambilla G, Ghirardello A, Romito A, et al. Antinuclear antibodies in recurrent idiopathic pericarditis: prevalence and clinical significance. Int J Cardiol. 2009;136(3):289-93. https://doi.org/10.1016/j.ijcard.2008.05.020.

71. Assayag M, Abbas R, Chanson N, Perozziello A, Ducrocq G, Alexandra J-F, et al. Diagnosis of systemic inflammatory diseases among patients admitted for acute pericarditis with pericardial effusion. J Cardiovasc Med (Hagerstown). 2017;18(11):875-80. https://doi.org/10.2459/JCM.0000000000000576.

72. Morel N, Bonjour M, Le Guern V, Le Jeunne C, Mouthon L, Piette J$\mathrm{C}$, et al. Colchicine: a simple and effective treatment for pericarditis in systemic lupus erythematosus? A report of 10 cases. Lupus. 2015;24(14):1479-85. https://doi.org/10.1177/0961203315593169.

73. Melboucy-Belkhir S, Compain C, Sacré K, Bussone G, Chauveheid M-P, Pasi N, et al. Recurrent acute pericarditis in Takayasu arteritis. Int J Cardiol. 2013;166(1):263-5. https://doi.org/10.1016/j.ijcard. 2012.09.106.

74. Yoshida S, Takeuchi T, Sawaki H, Imai T, Makino S, Hanafusa T. Successful treatment with tocilizumab of pericarditis associated with rheumatoid arthritis. Mod Rheumatol. 2012;24(4):10-3. https://doi.org/10.1007/s10165-012-0805-8.

75. Iwai A, Naniwa T, Tamechika S, Maeda S. Short-term add-on tocilizumab and intravenous cyclophosphamide exhibited a remissioninducing effect in a patient with systemic lupus erythematosus with refractory multiorgan involvements including massive pericarditis and glomerulonephritis. Mod Rheumatol. 2017;27(3):529-32. https://doi. org/10.3109/14397595.2014.990409.

76. Lee Y, Schulte DJ, Shimada K, Chen S, Crother TR, Chiba N, et al. Interleukin- $1 \beta$ is crucial for the induction of coronary artery inflammation in a mouse model of kawasaki disease. Circulation. 2012;125(12): 1542-50. https://doi.org/10.1161/CIRCULATIONAHA.111.072769.

77. Cavalli G, Pappalardo F, Mangieri A, Dinarello CA, Dagna L, Tresoldi M. Treating life-threatening myocarditis by blocking interleukin-1. Crit Care Med. 2016;44(8):e751-4. https://doi.org/10. 1097/CCM.0000000000001654.

78. Ozen S, Demirkaya E, Erer B, Livneh A, Ben-Chetrit E, Giancane $\mathrm{G}$, et al. EULAR recommendations for the management of familial Mediterranean fever. Ann Rheum Dis. 2016;75(4):644-51. https:// doi.org/10.1136/annrheumdis-2015-208690.

79. ter Haar NM, Oswald M, Jeyaratnam J, Anton J, Barron KS, Brogan PA, et al. Recommendations for the management of autoinflammatory diseases. Ann Rheum Dis. 2015;74(9):163644. https://doi.org/10.1136/annrheumdis-2015-207546.

80. Ozaki Y, Tanaka A, Shimamoto K, Amuro H, Kawakami K, Son Y, et al. A case of rheumatoid pericarditis associated with a high IL-6 titer in the pericardial fluid and tocilizumab treatment. Mod Rheumatol. 2011;21(3):302-4. https://doi.org/10.1007/s10165010-0377-4

81. Yoshida S, Takeuchi T, Sawaki H, Imai T, Makino S, Hanafusa T. Successful treatment with tocilizumab of pericarditis associated with rheumatoid arthritis. Mod Rheumatol. 2014;24(4):677-80. https://doi.org/10.3109/14397595.2013.874733.

82. Kamata Y, Minota S. Successful treatment of massive intractable pericardial effusion in a patient with systemic lupus erythematosus with tocilizumab. BMJ Case Rep. 2012;2012:bcr2012007834. https://doi.org/10.1136/bcr-2012-007834.

83. Ocampo V, Haaland D, Legault K, Mittoo S, Aitken E. Successful treatment of recurrent pleural and pericardial effusions with tocilizumab in a patient with systemic lupus erythematous. BMJ Case Rep. 2016;2016:bcr2016215423. https://doi.org/10.1136/bcr-2016-215423.

84. Hua A, O'Gallagher K, Sado D, Byrne J. Life-threatening cardiac tamponade complicating myo-pericarditis in COVID-19. Eur Heart J. 2020;41(22):2130. https://doi.org/10.1093/eurheartj/ehaa253.

85. Mehta P, McAuley DF, Brown M, Sanchez E, Tattersall RS, Manson JJ. COVID-19: consider cytokine storm syndromes and immunosuppression. Lancet. 2020;395(10229):1033-4.

Publisher's Note Springer Nature remains neutral with regard to jurisdictional claims in published maps and institutional affiliations. 